\title{
The use of eHealth to design a regional health promotion program in the workplace: Institute of Costa Rican Electricity case series
}

\author{
Anton Zamora-Ilarionov ${ }^{1,2}$, Laura Rodriguez ${ }^{3}$ \\ ${ }^{1}$ Translational Nutrition Research and Innovation Center (CIINT), San José, Costa Rica; ${ }^{2}$ School of Medicine, Hispano-American University, San \\ José, Costa Rica; ${ }^{3}$ Department of Occupational Health, Institute of Costa Rican Electricity, San José, Costa Rica \\ Correspondence to: Anton Zamora-Ilarionov, MS, CIINT Research Center, Av 9, Americas, San José, Costa Rica. Email: anternex@gmail.com.
}

\begin{abstract}
The development of sustainable health promotion programs in the workplace requires a coordinated systematic approach. Costs and resources often cause barriers to implement workplace programs in low-and middle-income countries. The objective of the case series is to evaluate the feasibility of health informatics to evaluate and monitor the physical activity and dietary habits of individuals in the workplace on a small scale as a preparation to implement the health promotion program across a company in Costa Rica. Participants were 25 employees where 17 participants had a body mass index (BMI) of $25.0 \mathrm{~km} / \mathrm{m}^{2}$ or more. This case series assesses and evaluates patient data during an 8-week period using multiple tools of eHealth technologies such as an Electronic Health Record (EHR), a Personal Health Record (PHR), electronic surveys and fitness trackers with compatible mobile applications. Adherence to wearing Fitbit was high and stable with a mean of $97.5 \%$ over 30 days $(n=16)$. The participants in the first week walked on average 8,239 steps but, at the end of the fourth week, the average steps decreased to 7,798. The dietary electronic survey was answered satisfactorily by $86.6 \%$ of the employees $(n=25)$. The employees scored on average 35 out of 100 on a diet quality scale. The consumption of vegetables, beans, whole grains, nuts and seeds is lower than the recommended dietary guidelines of 60 . The integration of eHealth technologies can provide a clearer understanding of the employees' health situation to more appropriately allocate efforts to promote behavior change where needed most.
\end{abstract}

Keywords: Workplace; mobile Health; electronic Health; mHealth; eHealth; case report

Received: 14 November 2019; Accepted: 03 June 2020; Published: 05 October 2020.

doi: $10.21037 /$ mhealth-19-231

View this article at: http://dx.doi.org/10.21037/mhealth-19-231

\section{Background}

The workplace has been identified by the World Health Organization (WHO) as an effective space to implement health initiative programs to promote healthy eating habits and physical activity. According to WHO, the three main benefits of occupational health programs are (I) changing lifestyle behaviors-such as improving physical activity and dietary habits; (II) improving health-related outcomessuch as reducing body mass index (BMI), reducing blood pressure and other cardiovascular disease risk factors; and (III) facilitating organizational-level changes-such as reduced absenteeism (1).

The use of eHealth programs in the workplace has resulted in positive outcomes for improving employee health in developed countries. In a systematic review conducted in the United Kingdom, 14 out of 25 studies evaluated reported a significant increase in physical activity, and 11 out of 16 studies reported an impact on the reduction of weight, systolic pressure and cholesterol (2).

However, there is little evidence about the use of eHealth in the workplace in low- and middle-income countries (LMICs). The main reason is due to the slow adoption and adaptation of eHealth, primarily linked to the scarcity of government investments within the technological infrastructure sector. According to the third eHealth report of the WHO, the percentage of implemented Electronic Health Record (EHR) systems is highest in wealthier 


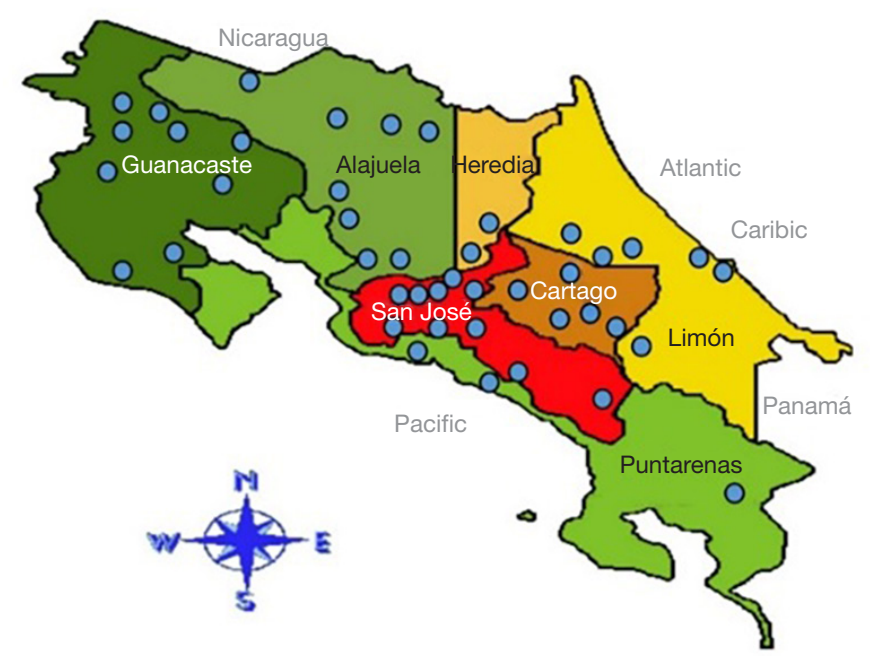

Figure 1 Location of ICE health centers. ICE, Costa Rican Institute of Electricity.

countries with two thirds $(66 \% ; \mathrm{n}=21)$ in the upper-middle income group and roughly half of high-income countries ( $52 \% ; \mathrm{n}=23$ ) have introduced EHR systems, while only a third of lower-middle-income countries $(35 \% ; n=10)$, and $15 \%$ of low-income countries $(n=3)$ reported having implemented EHR systems (3).

The development of eHealth and mHealth solutions, such as the EHR, reveal the causes of health situations across the globe within companies-specifically causes of sick-leave, health conditions and main diseases.

It is interesting to consider if the results of interventions in developed countries have the same impact on LMICs considering the different population groups, cultures and digital literacy as well as what types of sustainable technologies and interventions can be implemented. We present the following case in accordance with the CARE reporting checklist (available at http://dx.doi.org/10.21037/ mhealth-19-231).

\section{Case presentation}

\section{Health data collection and promotion for health centers across regions}

In the Central American country, Costa Rica, the legislation establishes that companies are responsible to implement and promote health and safety programs at the workplace. For example, companies with more than 10 employees must have an occupational health team and subscribe to social security to provide medical services on site (4).
The Costa Rican Institute of Electricity (ICE) is an autonomous governmental organization responsible for the electrical production and telecommunications for the entire country. The company itself has a population of 12,977 employees and 46 clinics distributed throughout Costa Rica, see Figure 1. The main functions of these health centers are to provide services of general medicine, occupational medicine, referrals to specialized medicine, attention to minor occupational accidents, and health promotion.

According to Figure 1, it can be noted that the ICE Health Services Network has national coverage with centers located across all seven provinces for its employees with seven health centers centralized in the capital of San José. One of the main issues ICE has experienced at the health centers across the departments is with the monitoring and follow-up of each employee's health.

Since July 2016, ICE has implemented an EHR in all 46 clinics allowing the collection of clinical information to analyze the specific needs of each employee as a result of digitalization.

The data from the ICE EHR reporting system shows that $49.1 \%$ of their employees are suffering from being overweight and/or obese.

Due to the identified health problem, the ICE Health Services department decided to develop a pilot project using mobile health, fitness trackers, and Personal Health Records (PHR) as the first stage to understand the habits of the employees. Based on the preliminary findings, a plan will be developed to design a sustainable health promotion program to reduce those who are overweight and/or obese.

The objectives of the pilot project were to identify the most 


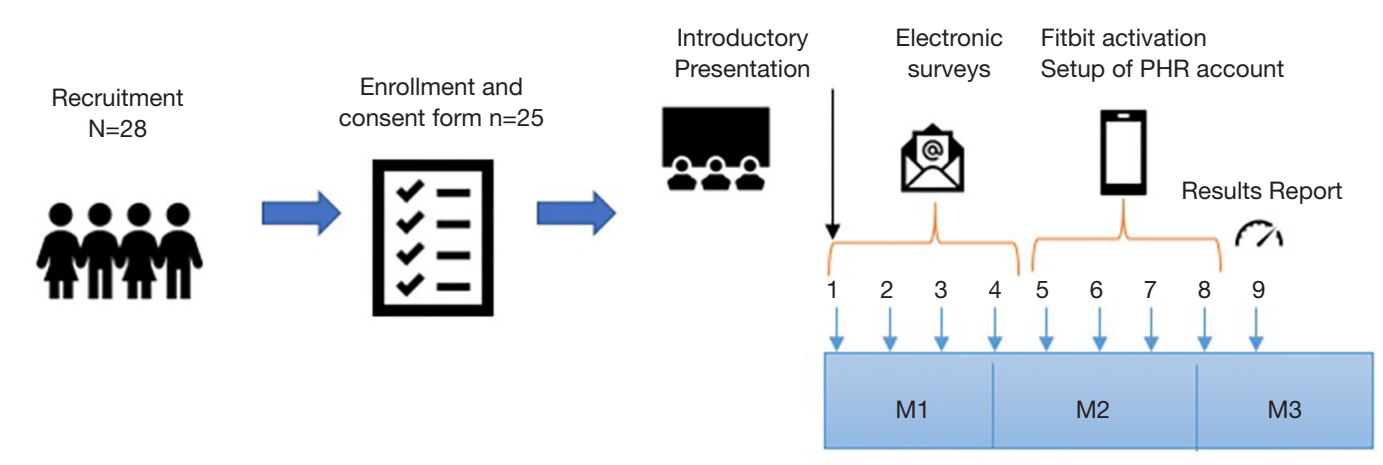

Figure 2 Design of the 8-week pilot project.

efficient and effective way to evaluate and monitor the physical activity, sleep quality and food consumption of the selected ICE employees and also to identify if the PHR, Fitbit tracker and electronic surveys are tools that could allow a large scale and sustainable monitoring of the health of employees.

\section{Design and methodology}

\section{Participants}

Out of the 36 departments of ICE, the selected participant group was Human Resources, the smallest department. The 8 -week pilot project had a population of 28 employees who were invited to participate voluntarily. Of the 28 invited, only 25 employees agreed to participate. All of the participants were regular Internet users, owned a computer and a smart phone. There were 17 employees that had a BMI over $25.0 \mathrm{~km} / \mathrm{m}^{2}$, 9 were overweight, 13 had obesity, 1 employee with diabetes, 1 with a diagnosis of dyslipidemia, and 7 employees with high blood pressure.

To start the pilot project, an introductory presentation was given on site at ICE in San José on September 2, 2019 (Figure 2).

\section{Fitbit and Fitbit mobile app}

After the introductory presentation, each employee signed a consent form and received a Fitbit Inspire HR along with training on how to use the Fitbit and the Fitbit mobile application.

\section{PHR}

According to the Fitbit Data Protection Policy, to gain access to the employees' information each user must provide consent to the third party requesting access to their information. For that reason, it was necessary to generate a PHR for every participant of the pilot project. This PHR works as a platform for the employees to have access to their health information, to schedule a doctor's appointment, among other useful functionalities. It was necessary for every employee to sync the Fitbit device with their individual PHR by clicking the integration link they received in an email for the data to be continuously collected throughout the duration of the pilot project. This was explained during the introductory presentation.

\section{Electronic surveys}

Survio software was used to create and send the electronic surveys. Four digital surveys were sent: (I) sociodemographic and health characteristics, (II) food frequency questionnaire (FFQ), (III) dietary practices, (IV) experience and satisfaction using Fitbit. The approximate duration to complete each survey was 15 minutes. Automatic reminders were sent via Survio to those who did not answer the surveys initially.

\section{Data collection}

The first electronic survey, sociodemographic and health characteristics, reports age, gender, address, education, occupation, and income. The health section reports if the participant is a smoker/non-smoker and physical activity. The second survey captured dietary information from the past year using an updated version of the FFQ. The third survey, dietary practices, reports basic nutritional knowledge as well as behavioral and normative beliefs associated with 


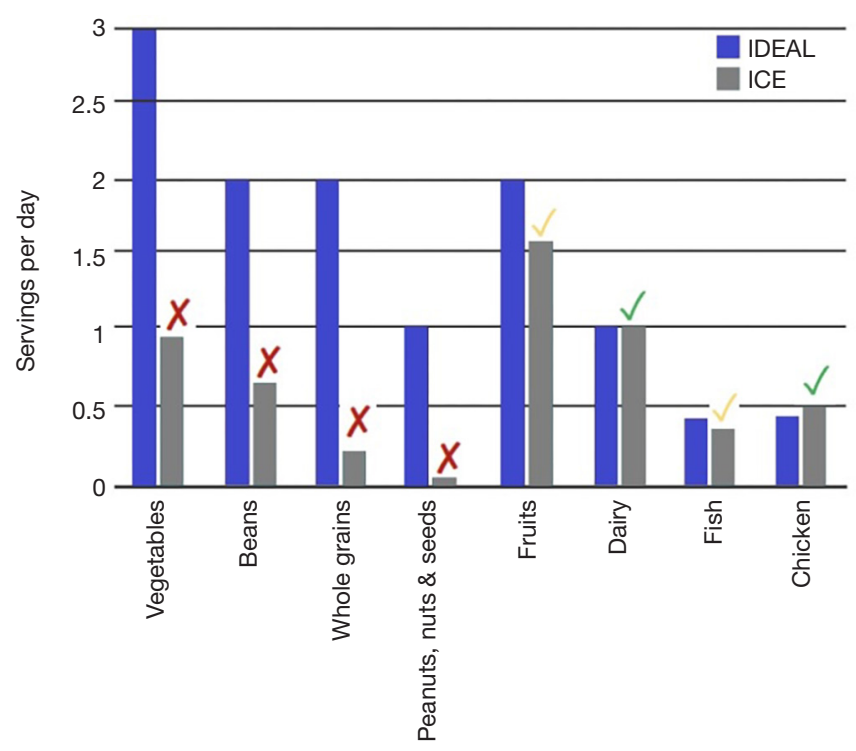

Figure 3 Average daily food intake of the employees.

food intake. The fourth survey asks employees to rate their experience with Fitbit use satisfaction and their willingness to use mobile technologies to improve their health in the future.

Fitbit was used to capture physical activity, number of steps per day and hours of sleep.

All the data was anonymized and SAS 9.4 was used for data analysis.

\section{Results}

The first electronic survey was answered by 21 employees $(84 \%)$, the second survey was answered by 20 employees $(80 \%)$, and the third survey by 24 employees $(96 \%)$.

Figure 3 seen below demonstrates the distribution of the dietary electronic surveys was useful in obtaining an $80 \%$ response rate from the employees $(n=20)$. These results reveal the average amount of quantities consumed in the varying food groups by the participants. The high percentage of response rate accurately depicts the average amount of consumption of vegetables, beans, whole grains and nuts and seeds are lower than the recommended dietary guidelines (5-10). However, the results indicate that the consumption of fruits, dairy, fish and chicken were within the recommended dietary amounts.

The results identify the need for food intake improvement and an increase in physical activity on average for the employees.

\section{Fitbit results}

\section{Adherence to tracker usage}

From 25 employees, only 16 employees (64\%) integrated the Fitbit to the PHR, and the others were unable to export the data. The 16 employees adhered well to wearing the Fitbit tracker, wearing the tracker during 97.5\% of intervention days. At the end of the evaluation, the electronic survey rating satisfaction found that the use of the Fitbit tracker had an outstanding acceptance rate with 21 of the 25 employees indicated feeling satisfied or very satisfied with the overall use of the device with only 4 employees indicating moderate satisfaction. Therefore, the majority of the employees (95\%) indicated that Fitbit assisted in improving awareness of their health and lifestyle choices (Figure 4).

During the first week of evaluation, the 16 employees with the tracker integrated walked on average 8,239 steps and the fourth and final week of evaluation revealed the average amount of steps decreased to 7,798 steps. It can be interpreted that due to the novelty of using a monitoring device for the first time, this caused employees to become more aware of walking, but over time this diminished (Figure 5).

The functionality that employees found most useful was the measurement of the number of steps with $69.6 \%$ followed by monitoring of sleep hours with $60.9 \%$ (Figure 6).

A notable number of employees, $34.8 \%$, indicated that 


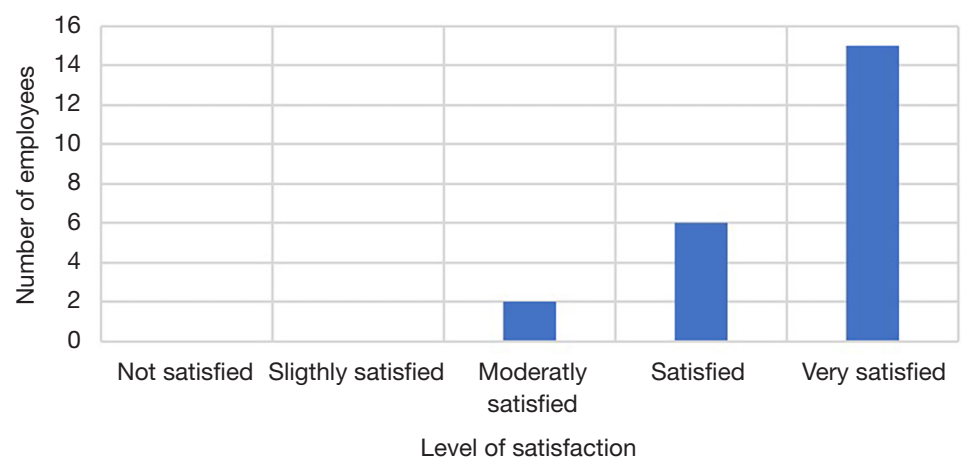

Figure 4 Satisfaction level of ICE Fitbit users, October 2019, n=25. ICE, Costa Rican Institute of Electricity.

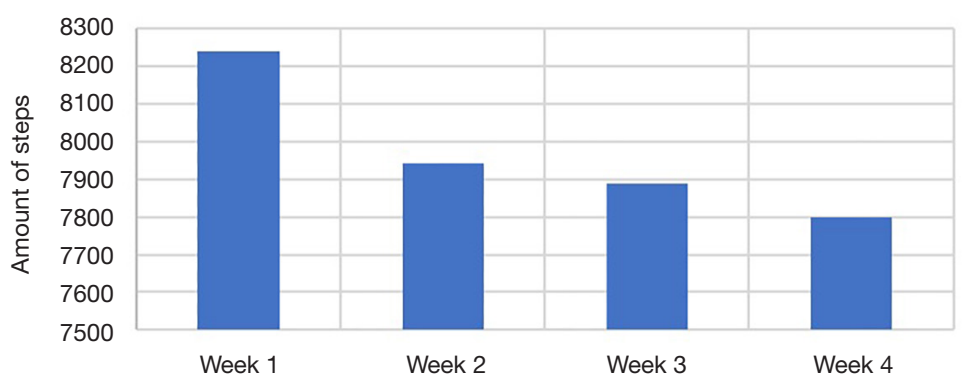

Figure 5 Average steps of employees per week for four weeks, $n=16$.

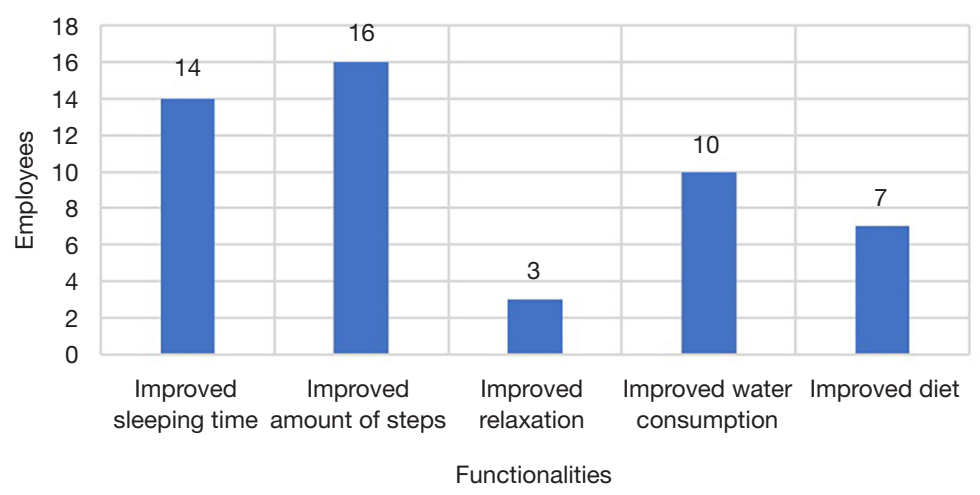

Figure 6 Fitbit functionality rankings according to improved health awareness, $n=25$.

the use of Fitbit was complicated. This may be related to the average age of the employees, which was 42 years. Therefore, more extensive research is required to assess whether Fitbit can maintain motivation in the working population of ICE and if there are subgroups of people who find it more effective to use the Fitbit tracker and app.

\section{Lessons learned}

The synchronization of the PHR was not favorable, only $11 \%$ of employees managed to sync the Fitbit to the PHR independently. More education and improvement of the user experience is required for larger implementations. Also, it may be beneficial to consider IT support and a help 
desk service to support issues and problems related with the use of the technology.

The electronic surveys were an effective tool to collect information and evaluate the health of the employees.

\section{Limitations}

The limitations of the pilot project were the amount of Fitbits budgeted for the use of this pilot project (number of fitbits $=30$ ). The lack of technological support to assist the employees in the digital integration requirements was also a limitation. The pilot project comprised a small sample of a relatively homogenous group (office employees with computer skills and access to smartphones), and results could not be generalizable across the company. The intervention period was relatively short, the long-term use of Fitbit tracker and its relationship with increasing physical activity could not be assessed. The results of the electronic surveys were shared with the participants but more research is necessary to evaluate the impact on self-awareness and dietary improvement.

During the 30-day period, only 16 employees were able to share the data. More research is required to understand if the other 9 employees were not comfortable sharing personal information or if there was technological difficulty or digital illiteracy.

For future research, it's recommended to take into account the entire spectrum of workplace employees in order to evaluate the effectiveness of implementing technological interventions in LMIC.

\section{Discussion}

The use of fitness trackers, such as Fitbit, can generate a motivational effect on a person, based on the results of the pilot project, however this initial motivation may decline over time. Interventions in mHealth have fallen short in determining if wearables or Mobile apps working independently manage to increase physical activity routines or change eating habits in a sustained manner $(2,11-13)$. More research is required to understand the disposition of employees on sharing personal data with companies.

The use of electronic surveys to gather nutritional habits proved to be very effective in this population group. Employees from other departments may not have the same digital literacy, access to computers or the time to fill out the electronic surveys, however.

The EHR is essential to integrate employees' information from different sources to analyze their physical health and how this can be affected by factors related to the workplace, such as stress, malnutrition and/or lack of physical activity. The average health issues, such as being overweight and obesity, are major contributors to non-communicable diseases (NCDs) (14). The NCD epidemic in LMICs has been attributed to higher life expectancy, globalization, urbanization, and unequal economic development (15). However, efficacy trials clearly demonstrate that lifestyle modification can prevent and control common chronic diseases (16-18).

The employee PHR must be more user friendly and have functionalities for the employee to make it more attractive as well as having the essential tools to interpret it.

\section{Adoption of a sustainable bealth in the workplace program}

In order to develop a sustainable health in the workplace program, efforts must be coordinated, organized and systematic. The framework provided by the Center for Disease Control and Prevention suggests a model based on 4 steps: (I) workplace health assessment; (II) planning and design the program; (III) implement the program; and (IV) determine impact through evaluation (19). To accelerate the implementation of sustainable health programs at the workplace in LMICs, the use of electronic health records and mobile health applications can be used to help reduce implementation costs $(20,21)$. This can speed up data capturing and communication as well as baseline evaluation, monitoring, execution and evaluation of results in remote sites and within large populations.

\section{Conclusions}

This case series is an initial contribution to explore the best use of digital health solutions in the design of sustainable health in the workplace programs in LMIC.

The integration of eHealth technologies can provide a clearer understanding of the employees' health situation to more appropriately allocate efforts to promote behavior change where needed most.

\section{Acknowledgments}

Funding: None.

\section{Footnote}

Provenance and Peer Review: This article was commissioned 
by the Guest Editors (Carinne Brody and Sarah Sullivan) for the series "Digital Interventions for Hard-to-reach Populations" published in mHealth. The article was sent for external peer review organized by the Guest Editors and the editorial office.

Reporting Checklist: The authors have completed the CARE reporting checklist. Available at http://dx.doi.org/10.21037/ mhealth-19-231

Conflicts of Interest: Both authors have completed the ICMJE uniform disclosure form (available at http:// dx.doi.org/10.21037/mhealth-19-231). The series "Digital Interventions for Hard-to-reach Populations" was commissioned by the editorial office without any funding or sponsorship. The authors have no other conflicts of interest to declare.

Ethical Statement: The authors are accountable for all aspects of the work in ensuring that questions related to the accuracy or integrity of any part of the work are appropriately investigated and resolved. All procedures performed in studies involving human participants were in accordance with the ethical standards of the institutional and/or national research committee(s) and with the Helsinki Declaration (as revised in 2013). The patient has given their consent for the case series to be published.

Open Access Statement: This is an Open Access article distributed in accordance with the Creative Commons Attribution-NonCommercial-NoDerivs 4.0 International License (CC BY-NC-ND 4.0), which permits the noncommercial replication and distribution of the article with the strict proviso that no changes or edits are made and the original work is properly cited (including links to both the formal publication through the relevant DOI and the license). See: https://creativecommons.org/licenses/by-nc-nd/4.0/.

\section{References}

1. WHO । Preventing Noncommunicable Diseases in the Workplace through Diet and Physical Activity [Internet]. WHO. [cited 2018 Aug 27]. Available online: http://www. who.int/dietphysicalactivity/workplace/en/

2. Buckingham SA, Williams AJ, Morrissey K, et al. Mobile health interventions to promote physical activity and reduce sedentary behaviour in the workplace: A systematic review. Digit Health 2019;5:2055207619839883.
3. WHO I Global diffusion of eHealth: Making universal health coverage achievable [Internet]. WHO. [cited 2019 Nov 12]. Available online: http://www.who.int/goe/ publications/global_diffusion/en/

4. Sistema Costarricense de Información Jurídica [Internet]. [cited 2019 Nov 12]. Available online: http://www.pgrweb. go.cr/scij/Busqueda/Normativa/Normas/nrm_texto_ completo.aspx? param $1=$ NRTC $\&$ nValor $1=1 \&$ nValor $2=810$ $04 \&$ nValor $3=103114 \&$ strTipM=TC

5. Willett W, Rockström J, Loken B, et al. Food in the Anthropocene: the EAT-Lancet Commission on healthy diets from sustainable food systems. Lancet 2019;393:447-92.

6. Mattei J, Sotos-Prieto M, Bigornia SJ, et al. The Mediterranean Diet Score Is More Strongly Associated with Favorable Cardiometabolic Risk Factors over 2 Years Than Other Diet Quality Indexes in Puerto Rican Adults. J Nutr 2017;147:661-9.

7. McCullough ML, Feskanich D, Stampfer MJ, et al. Diet quality and major chronic disease risk in men and women: moving toward improved dietary guidance. Am J Clin Nutr 2002;76:1261-71.

8. Sotos-Prieto M, Bhupathiraju SN, Mattei J, et al. Changes in Diet Quality Scores and Risk of Cardiovascular Disease Among US Men and Women. Circulation 2015;132:2212-9.

9. Sotos-Prieto M, Baylin A, Campos H, et al. Lifestyle Cardiovascular Risk Score, Genetic Risk Score, and Myocardial Infarction in Hispanic/Latino Adults Living in Costa Rica. J Am Heart Assoc 2016;5:e004067.

10. Luan D, Wang D, Campos H, et al. Red meat consumption and metabolic syndrome in the Costa Rica Heart Study. Eur J Nutr 2020;59:185-93.

11. Puigdomenech Puig E, Robles N, Saigí-Rubió F, et al. Assessment of the Efficacy, Safety, and Effectiveness of Weight Control and Obesity Management Mobile Health Interventions: Systematic Review. JMIR Mhealth Uhealth 2019;7:e12612.

12. Direito A, Carraça E, Rawstorn J, et al. mHealth Technologies to Influence Physical Activity and Sedentary Behaviors: Behavior Change Techniques, Systematic Review and Meta-Analysis of Randomized Controlled Trials. Ann Behav Med 2017;51:226-39.

13. Mason MR, Ickes MJ, Campbell MS, et al. An Incentivized, Workplace Physical Activity Intervention Preferentially Increases Daily Steps in Inactive Employees. Am J Health Promot 2018;32:638-45.

14. Obesity and overweight [Internet]. World Health 
Organization. [cited 2019 Sep 12]. Available online: http:// www.who.int/news-room/fact-sheets/detail/obesity-andoverweight

15. Lim SS, Vos T, Flaxman AD, et al. A comparative risk assessment of burden of disease and injury attributable to 67 risk factors and risk factor clusters in 21 regions, 1990-2010: a systematic analysis for the Global Burden of Disease Study 2010. Lancet 2012;380:2224-60.

16. Esposito K, Maiorino MI, Ceriello A, et al. Prevention and control of type 2 diabetes by Mediterranean diet: A systematic review. Diabetes Res Clin Pract 2010;89:97-102.

17. Aune D, Keum N, Giovannucci E, et al. Whole grain consumption and risk of cardiovascular disease, cancer, and all cause and cause specific mortality: systematic review and dose-response meta-analysis of prospective studies.

doi: $10.21037 /$ mhealth-19-231

Cite this article as: Zamora-Ilarionov A, Rodriguez L. The use of eHealth to design a regional health promotion program in the workplace: Institute of Costa Rican Electricity case series. mHealth 2020;6:44.
BMJ 2016;353:i2716.

18. Ajala O, English P, Pinkney J. Systematic review and metaanalysis of different dietary approaches to the management of type 2 diabetes. Am J Clin Nutr 2013;97:505-16.

19. Workplace Health Model I Workplace Health Promotion I CDC [Internet]. [cited 2019 Sep 12]. Available online: https://www.cdc.gov/workplacehealthpromotion/model/ index.html

20. Clifford GD. E-Health in Low to Middle Income Countries. J Med Eng Technol 2016;40:336-41.

21. Piette JD, Lun K, Moura LA, et al. Impacts of e-health on the outcomes of care in low- and middle-income countries: where do we go from here? Bull World Health Organ 2012;90:365-72. 